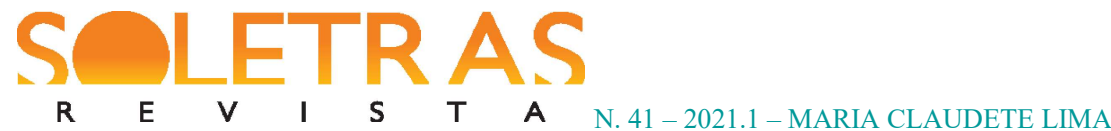

\title{
Tipologia de construções mediais em português: uma proposta cognitivo- funcional
}

\author{
Maria Claudete Lima ${ }^{1}$
}

\begin{abstract}
Resumo: Este ensaio propõe uma tipologia das construções médias em português, baseada no Modelo Cognitivo Idealizado de Causalidade de Langacker (1991a), chamado "bola de bilhar", e na noção de transitividade proposta por Hopper e Thompson (1980). Para tanto, discutem-se as características centrais da voz média e analisam-se, quanto à forma de codificação, à expressão da causa, ao tipo de evento, à motivação pragmática e à saliência das entidades, ocorrências retiradas do Corpus do Português NOW (DAVIES; FERREIRA, 2018), que abrange textos escritos do Brasil e de Portugal, de 2012 a 2019. Partindo da noção de construto absoluto de Langacker (1991a), propõe-se uma tipologia das construções médias em português, que se manifestam de forma lexical, sintática e perifrástica. Os resultados sugerem que as construções de voz inseridas no domínio medial são expressões distintas do mesmo construto de não atribuição de causalidade, o qual inclui ainda as construções passivas e impessoais.
\end{abstract}

Palavras-chave: Voz média. Causalidade. Construto absoluto.

\section{Introdução}

Tradicionalmente, a voz é estudada como categoria verbal que expressa uma relação entre o verbo e o sujeito. Em português, a Nomenclatura Gramatical Brasileira reconhece três vozes do verbo: ativa, passiva e reflexiva. Esta taxonomia não é adotada unanimemente nas gramáticas normativas do português. Rocha Lima (1992), por exemplo, admite apenas voz ativa e voz medial. Esta última recebe subclassificações para englobar alguns usos da construção clítica: medial-passiva (destruiu-se o casarão), medial-reflexiva (ele matou-se) e medial dinâmica (o gelo derreteu-se). Melo (1980) considera apenas voz ativa e passiva, descartando a voz reflexiva por ser acidental a correferencialidade entre a pessoa do objeto e do sujeito.

Esse tratamento diverso, brevemente ilustrado, deriva de as variadas manifestações da categoria de voz não se encontrarem claramente caracterizadas. Afinal, as distinções de voz em português não se correlacionam a desinências específicas. Assim, do ponto de vista

\footnotetext{
${ }^{1}$ Doutora e mestra em Linguística pela Universidade Federal do Ceará (UFC), é professora do curso de Letras e do Mestrado Profissional em Letras da UFC. Realiza estágio pós-doutoral na Universidade Presbiteriana Mackenzie. Ceará, Brasil. E-mail: claudete@ufc.br. ORCID iD: 0000-0002-9866-9209
} 
exclusivamente flexional, o verbo em português manifesta apenas a voz ativa (DUARTE, 2002).

Considerando-se, todavia, que uma categoria gramatical pode ser expressa não só por desinências, mas também por auxiliares e partículas (LYONS, 1979, p. 322), pode admitir-se, além da ativa, uma voz passiva em português expressa por auxiliar ser + particípio passado. Ainda assim, o estatuto da passiva como voz em português não é incontroverso. Camara Jr. (1985, p.165), por exemplo, considera que a construção passiva é uma oração nominal: "Do ponto de vista oracional, tem-se o mesmo tipo de frase em: (a) os soldados foram punidos; (b) os soldados foram covardes. (...) Assim, a chamada 'voz passiva' em português não tem caracterização morfológica”.

A dificuldade de caracterizar a categoria de voz em português se amplia com a inclusão das construções formadas com o clítico se. A distinção entre as variadas construções com clítico, se passivas, reflexivas ou nem uma nem outra, é explorada na literatura em diversas vertentes. De modo geral, reconhece-se o papel do contexto nessa diferenciação até mesmo em abordagens formais, como o faz Macambira (1986), ao tratar de voz reflexiva, recíproca e média.

A admissão do papel do contexto na diferenciação das construções de voz, especialmente as expressas por clítico, demonstra a insuficiência da caracterização formal, o que leva à proposição da voz como uma categoria essencialmente semântico-pragmática que ultrapassa a simples relação sujeito e verbo e atinge toda a oração. Essa concepção de voz encontra abrigo em uma abordagem cognitivo-funcional em que os limites entre léxico e gramática se diluem e em que as construções, entendidas como pareamento de uma estrutura conceitual complexa com um significante e uma função pragmática peculiar (GOLDBERG, 1995), formam um domínio conceitual ligado à noção de transitividade e causalidade.

Assim consideradas, as construções de voz situam-se em um continuum cujos extremos são, de um lado, o grau máximo de causalidade/transitividade, representado pela ativa prototípica, e, do outro, o grau mínimo de causalidade, representado pela média prototípica. O extremo mínimo dessa escala abriga uma variedade de construções que podem ser consideradas como membros de um mesmo domínio semântico-cognitivo. É o que se pretende discutir neste ensaio, tomando-se por base, principalmente, Langacker (1991a) e Kemmer (1993). 


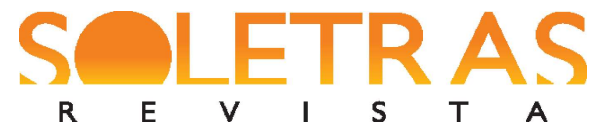

Para defender a caracterização do domínio médio em português como um fenômeno semântico-pragmático ligado à noção de causalidade, parte-se da noção de construto absoluto de Langancker (1991a) para se demonstrar, com dados do Corpus do Português NOW, como as variadas construções que se propõe inserir no domínio medial são expressões distintas do mesmo construto de não atribuição de causalidade.

\section{Voz e causalidade}

A dependência contextual na tipologia de construções de voz, sobre que se falou brevemente na seção anterior, é ilustrada pelas ocorrências a seguir, em que uma mesma codificação formal é interpretada como reflexiva (01), recíproca (02) e média (03).

(01) No país, vários casos já foram registrados de jovens (entre 12 e 18 anos) que se machucaram ou se feriram através do jogo. ${ }^{2}$

(02) Os dois, igualmente fortes e ferozes, atracaram-se rolando pelo chão. Machucaram-se um ao outro, cada um ferindo o inimigo sem piedade. ${ }^{3}$

(03) Segundo a emissora, entre as pessoas que se machucaram está Débora Ribeiro Rodrigues, de 33 anos, que foi levada para o Hospital Estadual de Sumaré (SP)....

Em (01), a notícia deixa claro que os jovens machucaram a si mesmos influenciados pelo jogo. Agiram sobre si como agiriam sobre outro participante, provocando em si mesmos os machucados. A ação parte do sujeito agente e atinge um objeto paciente, correferencial ao sujeito (CAMACHO, 2003). Em (02), similarmente a (01), o evento é provocado, mas, ao invés de agir sobre si mesmos, os participantes agiram um sobre o outro, exercendo ao mesmo tempo o papel de agente e paciente em relação a outro participante (MACAMBIRA, 1986). Em (03), o contexto de acidente esclarece que o efeito ocorreu de forma involuntária, a causa dos machucados não é atribuída a um agente volitivo, mas a um evento causativo, o acidente. O sujeito é o ponto de partida da mensagem e é afetado pelo processo tal como o referente do sujeito de (01), mas, diferentemente deste, não é o instigador do processo (KEMMER, 1993).

\footnotetext{
${ }^{2} \mathrm{https} / /$ jornalsantaterezanoticias.com.br/baleia-azul-uma-modinha-perigosa-da-internet-que-serve-de-alertapara-os-pais/

${ }^{3} \mathrm{https}: / /$ peregrinacultural.wordpress.com/2010/10/18/os-dois-leoes-fabula-de-florian/

${ }^{4} \mathrm{https} / / /$ noticias.uol.com.br/cotidiano/ultimas-noticias/2020/06/23/campinas-viatura-dos-bombeiros-atropelapedestres-durante-caso-de-incendio.htm
} 


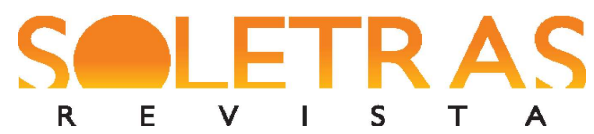

O fato de essas construções de voz dependerem de fatores sintático-semânticos leva ao reconhecimento da voz como um fenômeno não apenas morfossintático, restrito ao predicado, mas essencialmente como um fenômeno semântico-pragmático ligado a toda a oração (HALLIDAY, 1976 ${ }^{5}$. Assim concebida, a voz relaciona-se à transitividade, encarada não apenas como uma relação entre verbo e complemento - categoria discreta que divide os verbos em transitivos, se admitirem complemento, e intransitivos, se não admitirem — mas como uma propriedade semântica escalar mais geral, ligada à conceitualização de eventos, em que entram fatores relativos ao sujeito, ao objeto e ao verbo (HOPPER; THOMPSON, 1980; GIVÓN, 1993; SHIBATANI, 2006), tais como: (1) a quantidade de participantes; (2) a classificação semântica do verbo; (3) o contorno têmporo-aspectual do evento; (4) a modalidade e o tipo de frase; (5) a agentividade do sujeito; (6) a afetação e individuação do objeto.

Todos os parâmetros definidores da transitividade são relativos à efetividade com que uma ação toma lugar e é transferida de um participante a outro ${ }^{6}$. Em outras palavras, tais parâmetros ressaltam a relação entre a transitividade e a noção de causalidade (DELANCEY, $1987)^{7}$, compreendida conceitualmente como a transmissão de energia de um participante a outro, noção que dá lugar à visão metafórica de um trajeto que começa no sujeito, entendido como fonte, e termina no objeto, entendido como meta.

Essa metáfora deriva de uma concepção de mundo em que objetos discretos se movem no espaço, entram em contato uns com os outros e participam de interações energéticas (LANGACKER, 1991a). O movimento dos objetos é comandado por energia (ou força), que alguns retiram de recursos internos e outros recebem do exterior. Assim, além da força ou energia (interação), são elementos do Modelo Cognitivo Idealizado $(\mathrm{MCI})^{8}$ da

\footnotetext{
${ }^{5}$ Halliday (1976) distingue voz do verbo, ligada à forma verbal, e voz da oração, relacionada aos papéis semânticos.

${ }^{6}$ Cabe lembrar que essa noção de "transferência" que está na origem do termo transitivo $(<$ lat. transitīvus $)$, derivado do latim transīre 'passar de um lugar a outro', também é atribuída aos verbos transitivos na gramática tradicional (CUNHA; CINTRA, 1985, ALMEIDA, 1980).

${ }^{7}$ DELANCEY (1987, p. 60) afirma que "a base natural do protótipo de transitividade é a compreensão humana universal de que os eventos têm causas, isto é, que a base do protótipo de transitividade é um simples esquema CAUSA $\rightarrow$ EFEITO que deve sua universalidade a sua utilidade universal em lidar com o mundo real. ("the natural basis for the transitivity protype is the universal human understanding of the physical fact that event have causes, i. e. that the basis of the transitivity prototype is a simple CAUSE $\rightarrow$ EFFECT schema which owes its universality to its universal utility in dealing with the real world").

${ }^{8}$ Modelo Cognitivo Idealizado é um tipo de construto, ligado à noção de Gestalt, inicialmente proposto por Lakoff (1987), que diz respeito ao modo como organizamos coerentemente o conhecimento enciclopédico de acordo com certos princípios cognitivos: os frames, os esquemas imagéticos e a metáfora e a metonímia (CIENKI, 2007).
} 


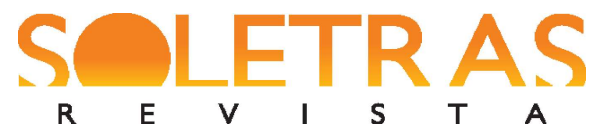

causalidade: o espaço (movimento), o tempo (mudança) e a substância material (objetos). Esses elementos compõem o modelo da bola de bilhar que representa uma cadeia de ação: um objeto faz forte contato com outro, resultando em transferência de energia. O segundo objeto entra em contato com outro, resultando de novo em transferência de energia e assim indefinidamente, até que a energia se acabe ou nenhum contato seja feito. O núcleo da cadeia é o objeto inicial, e a cauda é o objeto final. Em cadeias de ação mais simples, o núcleo e o fim interagem sem intermediários, há apenas dois objetos participantes. A figura 1, retirada de Langacker (1987, p.283), representa uma cadeia de ação.

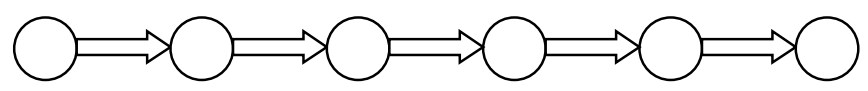

Figura 1: cadeia de ação (LANGACKER, 1987)

Essa conceitualização da experiência como uma rede causal se manifesta nas construções de voz. Frases ativas prototípicas, como (04), codificam um evento causativo canônico, em que há dois participantes numa relação assimétrica, um dos quais é agente arquetípico: "pessoa que voluntariamente inicia uma atividade física, resultando, através de contato físico, numa transferência de energia a um objeto externo"", e o outro, um paciente também arquetípico: "objeto inanimado que absorve a energia transmitida via contato físico iniciado externamente e, por isso, experimenta uma mudança de estado"10.

(04) Gonzálezag chutou a bola $\mathrm{pac}_{\mathrm{pac}}$ e derrubou Celso Borges pac $^{11}$

A voz ativa prototípica representa eventos causativos e apresenta alto grau de transitividade, conforme os parâmetros de Hopper e Thompson (1980). As demais vozes representam afastamentos dessa transitividade prototípica, codificando formas alternativas de conceber um evento, de modo a permitir diferentes tipos de oposição na estrutura do evento (CROFT, 1994).

\footnotetext{
${ }^{9}$ The archetypal agent is a person who volitionally initiates physical activity resulting, through physical contact, in the transfer of energy to an external object (LANGACKER, 1991a, p.285).

${ }^{10} \mathrm{An}$ inanimate object that absorbs the energy transmitted via externally initiated physical contact and thereby undergoes an internal change of state (LANGACKER, 1991a, p.285).

${ }^{11} \mathrm{https}$ //pt.besoccer.com/noticia/clima-quente-mensagens-anonimas-denunciam-racha-na-costa-rica-jogadoresnegam-451018
} 


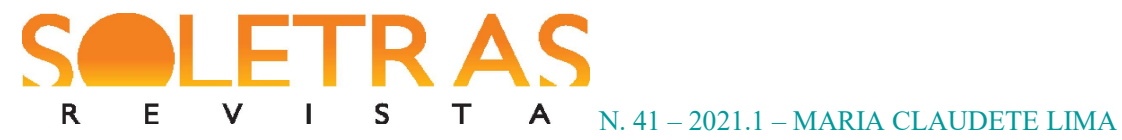

Como desvios do protótipo, as demais construções costumam ser formas marcadas e se caracterizam pelos três domínios da voz: (1) a impessoalização, que diz respeito à supressão ou demoção do agente; (2) a topicalidade, que está ligada à acessibilidade do referente, à importância temática e à perspectivação; (3) a detransitivização, que envolve decréscimo nas propriedades da transitividade (GIVÓN, 1982). Esses três domínios confluem em uma mesma construção, o que mostra que construções particulares se comportam como organismos complexos em que as dependências mútuas não são acidentais:

(a) se a identidade do agente é suprimida, um outro argumento pode ser tópico da oração, daí a confluência entre impessoalização e topicalidade; (b) se o aspecto perfectivo/estativo/resultativo de um evento é focalizado, presumivelmente o estatuto do agente é menos importante, daí a confluência entre detransitivização e impessoalização; (c) se o tópico da oração é não agentivo, é provável que aspectos relativos ao paciente do evento, isto é, o estado resultante sejam focalizados; daí a confluência entre topicalidade e detransitivização (GIVÓN, 1982, p.139).

Tal confluência entre os parâmetros evidencia o caráter complexo da categoria de voz e mostra como reduzi-la à forma verbal seria ignorar seu papel na codificação de variadas distinções conceituais discursivamente significativas, relativas à origem e ao modo de desenvolvimento do processo, à saliência dos participantes e à natureza do seu envolvimento com o evento (SHIBATANI, 2006).

Consideradas em suas dimensões semântico-pragmáticas, as construções que se afastam da ativa prototípica em português são: (1) passiva; (2) impessoal (CAMACHO, 2000); (3) reflexiva; (4) recíproca; (5) média (CAMACHO, 2003); e (6) estativa (CROFT, 1994). Tais distinções podem se expressar por meios lexicais, gramaticais e sintáticos (SHIBATANI, 2006). Na seção seguinte, discute-se a construção média, considerando suas relações com os demais tipos de voz.

\section{A voz média como construto absoluto}

A voz média, um dos afastamentos da ativa prototípica, é a codificação de um construto em que uma situação de mudança é concebida de modo esquemático, perfilando 


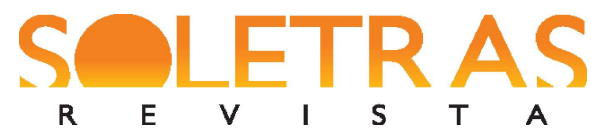

N. 41 - 2021.1 - MARIA CLAUDETE LIMA

apenas uma relação temática (BECOME $\rightarrow$ STATE). Especialmente em abordagens formais, costuma ser relacionada à inacusatividade, fenômeno lexical ou sintático, segundo o qual o verbo tem como sujeito um argumento interno (RAPOSO, 2013).

No nível lexical, consideram-se inacusativos verbos como adoecer, adormecer, desaparecer, desmaiar, morrer, nascer, que "denotam situações que afetam a entidade que corresponde ao sujeito e sobre as quais este não tem controle; ou seja, o sujeito dos verbos inacusativos é tipicamente um paciente ou um tema" (RAPOSO, 2013, p.1206), como em (05a).

No nível sintático, consideram-se orações inacusativas não só as formadas com verbos inacusativos, mas também as relacionadas a uma construção transitiva construída intransitivamente com valor incoativo (CIRÍACO; CANÇADO, 2004), como os pares de (06). Em (06a), tem-se uma construção ativa com o agente "a vítima" como ponto de partida e o tema 12 "a porta", como ponto de chegada. Em (06b), tem-se uma construção média construída apenas com o participante temático, denotando um processo de mudança não provocado.

(05) a.Fernando Gomes Freitas, conhecido como Fernandinho Guarabu, um dos traficantes mais procurados do Rio de Janeiro, morreu na manhã desta quinta-feira (27) durante confronto com policiais militares no Morro do Dendê, na Ilha do Governador, Zona Norte do Rio de Janeiro ${ }^{13}$.

b. Fernandinho Guarabu, um dos traficantes mais procurados do RJ, é morto pela polícia ${ }^{14}$.

c. Policiais militares encontraram e mataram, durante um confronto, Fernando Gomes Freitas, o Fernandinho Guarabu, na favela que ele chefiava, o Morro do Dendê, na Ilha do Governador, Zona Norte do Rio ${ }^{15}$.

(06) a. Quando a vítima abriu a porta, o homem teria dado vários chutes e $\operatorname{socos}^{16}$.

b. A polícia contou que o jovem de 19 anos estava pendurado na janela do carro. Quando o veículo fez uma curva, a porta abriu, ele perdeu o equilíbrio e caiu ${ }^{17}$.

\footnotetext{
${ }^{12}$ Para Langacker (1991a), Tema é um macropapel que abriga os papéis semânticos de paciente, movido e experienciador.

${ }^{13} \mathrm{https}: / /$ pleno.news/brasil/cidades/um-dos-maiores-traficantes-do-rj-e-morto-durante-confronto.html

${ }^{14} \mathrm{https}: / / \mathrm{www}$. agoramt.com.br/brasil/fernandinho-guarabu-um-dos-traficantes-mais-procurados-do-rj-e-mortopela-policia/80669

${ }^{15} \mathrm{https}: / / \mathrm{www}$. agoramt.com.br/brasil/fernandinho-guarabu-um-dos-traficantes-mais-procurados-do-rj-e-mortopela-policia/80669

${ }^{16} \mathrm{https}: / /$ www.nsctotal.com.br/noticias/mulher-e-agredida-e-ameacada-de-morte-com-arma-pelo-ex-namoradoem-blumenau

${ }^{17}$ https://g1.globo.com/sp/bauru-marilia/noticia/2019/01/18/jovem-cai-de-carro-em-movimento-e-sofretraumatismo-craniano-em-tupa.ghtml
} 
Do ponto de vista semântico, não há diferença na concepção básica de evento expressa em (05a) e (06b), ou em (05c) e (06a). Tanto em (05a) como em (06b), fala-se de um processo que acontece a uma entidade afetada: Fernando Gomes Freitas morreu, em (05a), e a porta abriu, em (06b). Em (05c), como em (06a), fala-se de uma entidade com controle [policiais militares, em (05c), e a vitima em (06a)] que age sobre outra entidade causando-lhe uma mudança de estado. A diferença, portanto, não é conceitual, mas formal. Em (05a) e (05c), a oposição se expressa no léxico, por meio do uso de verbos diferentes, morrer e matar, respectivamente. Em (06a) e (06b), a oposição se dá no plano da estruturação sintática: um mesmo verbo ${ }^{18}$ é empregado intransitivamente, com o paciente na posição de sujeito ou transitivamente, com o paciente como objeto direto.

Partindo-se de uma noção de voz essencialmente semântica, baseada na conceitualização de eventos, dentro de um quadro teórico em que "léxico e gramática formam uma gradação plenamente descrita como uma conjunção de estruturas simbólicas" (LANGACKER, 2000, p.1), não se justifica considerar tais fenômenos como distintos, apenas por a manifestação formal ser distinta, como bem defende Shibatani, (2006):

Assim como no caso das causativas, as construções médias manifestam-se em três tipos - lexical, morfológico, e perifrástico — tanto em línguas individuais como entre diferentes línguas. O balinês, por exemplo, exibe os três tipos de construção média, permitindo que alguns tipos de situação sejam expressos morfologicamente ou perifrasticamente. ${ }^{19}$ (SHIBATANI, 2006, p. 234)

Construções como (05a) e (06b) representam um construto absoluto, concepção de evento autônomo que abstrai qualquer fonte de energia e que é permitida pela autonomia conceitual da mudança de estado e do Tema, ou seja, da relação temática ${ }^{20}$ (LANGACKER, 1991b). Assim, em (07a), a seguir, a causação é conceitualmente dependente (D) da mudança de estado, *um homem quebrou, mas a mudança de estado é conceitualmente autônoma (A)

\footnotetext{
${ }^{18}$ Estamos desconsiderando aqui a hipótese de homonímia, para evitar discussão que nos afastaria do foco.

${ }^{19} \mathrm{Just}$ as in the case of causatives, middle constructions come in three types - lexical, morphological, and periphrastic — both within individual languages and across diferent ones. Balinese, for example, exhibits all three types of middle construction, allowing some situation types to be expressed either morphologically or periphrastically (SHIBATANI, 2006, p. 234).

${ }^{20}$ Langacker (1991b, p. 254) define relação temática como o núcleo conceitual de uma predicação processual: "a thematic relationship evolving through time constitutes the irreducible nucleus of an event conception".
} 


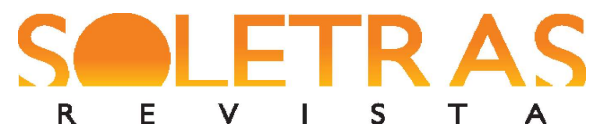

em relação à causação, uma vez que pode ser concebida sem referência à entidade causadora, como em (07b): o vidro quebrou, e conceitualmente autônoma em relação ao controle voluntário de um agente, pois pode ocorrer sem a concepção do controle voluntário: $A$ chuva quebrou o vidro.

(07) a. Segundo a Polícia Militar (PM), o atentado aconteceu durante o período de aula em a Escola Flora Calheiros, em o bairro Esperança de a Comunidade. Testemunhas relataram que um homem quebrou o vidro do veículo do professor $^{21}$

b. Em Guarulhos, o vidro de uma academia estilhaçou ${ }^{22}$. Clientes malhavam em o estabelecimento em o momento que o vidro quebrou, mas ninguém ficou ferido $^{23}$

Em geral, o componente autônomo tende a ser semanticamente mais específico, extensivo e concreto. Numa construção esquemática como $X$ quebrou $Y$, por exemplo, o componente $\mathrm{Y}$ tem mais informação substancial, mais extensão, que o componente $\mathrm{X}$, uma vez que é parcialmente delimitado pelo verbo a "entidades capazes de serem quebradas", mas $\mathrm{X}$ é aberto, possuindo apenas a noção de "fonte de energia". É essa carga semântica de Y que permite o construto absoluto, que consiste em perfilar o componente autônomo (A) independentemente do componente dependente (D), como nas frases citadas.

O contraste absoluto/energético, como matéria de construto, é independente da realidade objetiva e depende de convenções culturais e da escolha do falante (LANGACKER, 1991a). Em (05), por exemplo, o mesmo evento foi expresso como construto absoluto em (05a) e como construto energético em (05b) e (05c).

Embora as construções $(05 b)$ e $(05 c)$ representem um construto energético, há diferenças entre elas. Em (05b), a voz passiva perspectiva o evento energético a partir do final da cadeia de ação, que é mais saliente e tópico. Esta inversão do fluxo natural da energia, que normalmente parte da fonte para a meta, tem motivações pragmáticas, ligadas à topicalidade e à perspectivação (GIVÓN, 1993; CAMACHO, 2003) 24. Cognitivamente, Fernandinho

\footnotetext{
${ }^{21}$ https://g1.globo.com/ro/rondonia/noticia/2019/05/09/policia-civil-investiga-atentado-a-professor-em-escola-dero-carro-foi-incendiado.ghtml

${ }^{22}$ O contexto da notícia: "A chuva que caiu na Grande São Paulo desde a noite de segunda-feira (25) derrubou mais de 100 árvores na capital paulista e na Região Metropolitana e provocou estragos"

${ }^{23} \mathrm{https}: / / \mathrm{g} 1$.globo.com/sp/sao-paulo/noticia/2019/02/26/chuva-volta-a-deixar-toda-a-cidade-de-sp-em-estado-deatencao-apos-noite-chuvosa.ghtml

${ }^{24}$ A escolha do sujeito pode ser influenciada por uma série de fatores: papel semântico da entidade, hierarquia de empatia, definitude e organização Figura/Fundo (LANGACKER, 1991a). Todos esses fatores indicam a saliência cognitiva de um dado referente que pode ser escolhido como sujeito, que tem máxima topicalidade e alto grau de proeminência.
} 


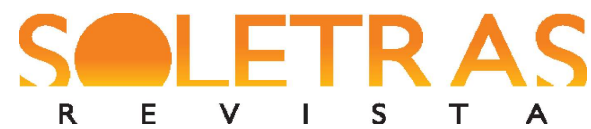

Guarabu, um nome próprio no singular, tem mais proeminência morfológica e é mais individuado que a polícia, um nome comum e coletivo (VESTERINEN, 2006). (05c) representa o evento em um caminho natural do fluxo de energia: da fonte de energia (os policiais militares) para a meta (Fernando Gomes Freitas). As frases (08a) e (08b), a seguir, codificam o mesmo evento também por meio de uma construção ativa como $(05 \mathrm{c})$, mas a fonte de energia de (08a) e (08b) é mais baixa em agentividade, porque é expressa por nomes abstratos, menos salientes cognitivamente: a operação matou o traficante - o tiroteio matou Guarabu.

(08) a. A Polícia Militar disse que as investigações sobre o envolvimento de policiais com traficantes do Dendê estão sob sigilo e que desde a última quinta-feira (27), dia da operação que matou o traficante Fernaninho Guarabu, a corregedoria da PM apreendeu $\mathrm{R} \$ 38$ mil em dinheiro ${ }^{25}$

b. Imagens mostram momento logo após tiroteio que matou Guarabu e comparsas $^{26}$

Do mesmo modo que a baixa agentividade representa baixa transitividade, conforme os parâmetros de Hopper e Thompson (1980), a causalidade, ligada à transitividade, também se submete à gradação a depender da saliência dos elementos nominais (LANGACKER, 1991a), como ilustram as construções (08a) e (08b).

A noção de causalidade, sendo matéria de construto e dependendo de escolhas do falante, nem sempre está explícita linguisticamente. Assim, um verbo, como cair, que normalmente denota um processo involuntário, pode ser usado para expressar um construto absoluto ou energético (LANGACKER, 1991a). Em (09), por exemplo, há uma oração com verbo media tantum (que caiu) encaixada em uma construção passiva com agente da passiva, semanticamente um instrumento que expressa a fonte de energia direta da mudança de estado construída autonomamente.

(09) Autoridades dos Estados Unidos acreditam que o avião ucraniano que caiu em Teerã, no Irã, foi derrubado por um míssil iraniano, informou a imprensa americana nesta quinta-feira $(9)^{27}$.

\footnotetext{
${ }^{25}$ https://g1.globo.com/rj/rio-de-janeiro/noticia/2019/06/29/mensagens-revelam-a-troca-de-dinheiro-porinformacoes-sobre-operacoes-da-pm-na-favela-do-dende-na-ilha-do-governador.ghtml

${ }^{26} \mathrm{https} / / /$ odia.ig.com.br/rio-de-janeiro/2019/06/5657946-imagens-mostram-momento-logo-apos-tiroteio-quematou-guarabu-e-comparsas.html

${ }^{27}$ https://g1.globo.com/mundo/noticia/2020/01/09/alguem-pode-ter-cometido-um-erro-diz-trump-sobre-quedade-aviao-ucraniano-no-ira.ghtml
} 
Partindo-se dessa frase conceitualmente autônoma, pode-se acrescentar camadas de alinhamento A/D (Autônomo/Dependente) (LANGACKER, 1991a), em que míssil como instrumento inanimado é menos causal que um agente humano, como em $\mathrm{C}$, que, por sua vez, parece menos causal que o agente humano em $\mathrm{D}$, pela volição pressuposta na causativa com o verbo mandar.

A. O avião caiu.

B. O avião foi derrubado por um míssil./ Um míssil derrubou o avião.

C. Os militares derrubaram o avião com um míssil.

D. As autoridades iranianas mandaram os militares derrubarem o avião com um míssil.

Cumpre lembrar que, em (06b), o mesmo verbo cair foi empregado, mas nesse contexto claramente denota-se um evento não provocado: ele perdeu o equilíbrio e caiu. Diferentemente de (09), em que se atribui o evento a um míssil (instrumento controlado por um agente), em (06b), o evento resulta de outro evento não controlado e não provocado: a perda de equilíbrio. As duas orações com cair em (09) e (06b) são mediais e codificam um processo que ocorreu a uma entidade em um espaço de tempo delimitado, embora, em uma, o evento pareça ter sido provocado e, na outra, seja claramente não provocado. A codificação linguística, nos exemplos (09) e (06b), não expressa a diferença da realidade objetiva, embora ofereça ao falante alternativas para representar diferentes concepções de evento.

\section{As construções médias lexical e sintática}

A existência de verbos lexicalmente marcados como verbos mediais, os chamados media tantum, como cair, mesmo em línguas como o grego clássico, que tem marcas desinenciais para a expressão da média, parece dever-se à naturalidade da concepção autônoma do evento expresso pelos verbos mediais (SHIBATANI, 2006). Em geral, são verbos que expressam ações que normalmente se situam na esfera do sujeito ou processos fisiológicos naturais (KEMMER, 1993).

Estes verbos, embora possam ser usados na voz ativa, são mais comuns na codificação média, denotando eventos espontâneos (SAID ALI, 1964). São verbos como envelhecer, 
adoecer, apodrecer, esfriar, derreter, entardecer, amadurecer e outros que expressam processos que se dão no sujeito de forma involuntária, por alguma causa interna ou força natural. (10a), por exemplo, expressa um processo que ocorre de modo espontâneo e afeta o sujeito. Nenhuma menção é feita a uma fonte de energia que provocou o evento, tido como natural $^{28}$. Já em (10b) a mudança de estado tornar-se velho é atribuída a uma fonte de energia externa - maquiagem, o evento passa a ser codificado como provocado e expresso por uma codificação ativa $^{29}$.

(10) a. No filme, é Earl Stone, um homem que envelheceu distante da família, mais interessado em cultivar e desenvolver novas espécies de flores. ${ }^{30}$

b. Mais recentemente, o ator divulgou uma foto sua já na metade da maquiagem que o envelheceu para a cena ${ }^{31}$

Como as construções exemplificadas em (05a) e (06b), (10a) também apresenta a noção de incoatividade, ou seja, expressa uma mudança de estado pontual (CASTILHO, $1968)^{32}$. Em outras palavras, codifica o desenvolvimento do processo focado na mudança de estado, a porção intermediária de um evento: BECOME $\rightarrow$ STATE, como ilustra a figura 2, adaptada de Croft (1994). Na figura, as frases (a), (b) e (c) representam diferentes visões de uma mesma situação que envolve mudança provocada: a quebra da janela por meio de uma pedra. A visão de evento causativa (a) engloba causa, mudança e estado. A visão incoativa (b) perfila, ao mesmo tempo, a mudança de estado e o resultado, e a visão estativa (c) perfila apenas o resultado, sem noção de movimento (normalmente expressa por verbos estativos, como estar).

\footnotetext{
${ }^{28} \mathrm{O}$ processo é desencadeado inevitavelmente pela passagem do tempo.

${ }^{29}$ Segundo Rio-Torto (2019, p.594), este é o uso predominante no português atual: "Com a evolução da língua, os verbos portadores de en- ... -ec- passam a denotar dominantemente processo com causador externo (enriquecer, emagrecer) e processos psicológicos (enfurecer, enlouquecer, enraivecer, entontecer)".

${ }^{30} \mathrm{https} / / / \mathrm{g} 1$.globo.com/bemestar/blog/longevidade-modo-de-usar/post/2019/02/03/a-licao-de-clint-eastwoodafinal-por-que-parar.ghtml

${ }^{31} \mathrm{http} / / / \mathrm{www}$.adorocinema.com/noticias/filmes/noticia-147961/

${ }^{32}$ Cançado e Godoy (2012) distinguem lexical e sintaticamente verbos como abrir e envelhecer, dentro de uma classe geral de verbos de mudança de estado, propondo três subclasses sintático-semânticas: (1) causativoagentivos, que admitem como sujeito agente ou causa e aceitam passivização (abrir, rasgar, queimar: X, voluntária ou involuntariamente, causa Y ficar aberto/rasgado/queimado); (2) estritamente causativos, formada apenas por alguns verbos psicológicos, que não admitem sujeito agente, apenas causa, nem aceitam passivização (preocupar, chatear, aborrecer: uma eventualidade X, evento ou estado,causa Y ficar preocupado, chateado, aborrecido); (3) incoativos, formada por verbos que expressam mudança de estado que dependem de propriedades inerentes ao argumento interno, não admitem agente como sujeito, apenas causa, e não aceitam cliticização nem passivização (amadurecer, adoecer, branquear: pode existir uma eventualidade X que causa (motiva) Y ficar maduro, doente, branco), esses últimos ligados à noção de espontaneidade.
} 
(a) Causativa: a pedra quebrou a janela.

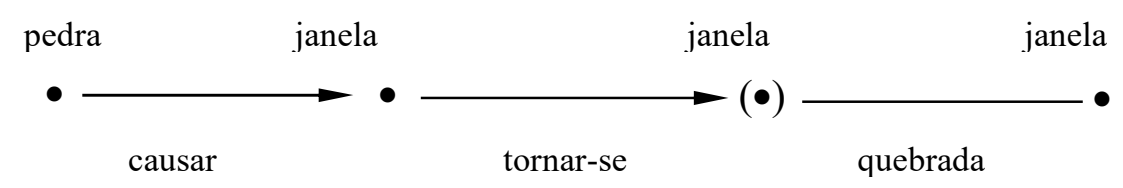

(b) Incoativa: a janela quebrou.

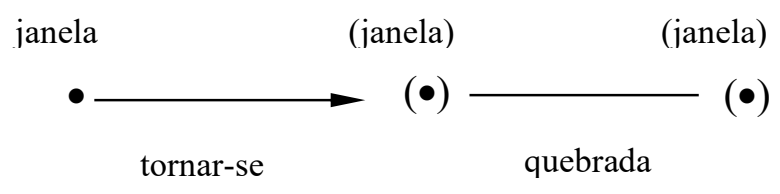

(c) Estativa: a janela está quebrada. janela (janela)

quebrada

Figura 2 - Estrutura interna de um evento, segundo Croft (1994)

A relação entre as estruturas (a) e (b) tem sido tratada na literatura como alternância causativa/incoativa (também chamada de causativa/anticausativa; causativa/inacusativa), fenômeno comum não só em português, mas em muitas outras línguas (ROŚCIŃSKAFRANKOWSKA, 2012; ALEXIADOU, 2015; WU; CIENKI, 2019), em que um mesmo verbo pode ser usado transitiva e intransitivamente, ou mais exatamente, ativa e medialmente, sem marcação por desinências ou perífrases. Tal possibilidade já está presente no sistema linguístico latino, em que, por exemplo, aceto, are 'azedar', derivado do adjetivo acetus, a, um 'azedo', podia significar tanto 'tornar azedo' como 'tornar-se azedo', como em vinumacetat 'o vinho fica azedo', em que se expressa a mudança de estado espontânea por um verbo intransitivo sem marcas formais (DUARTE, 1990).

Esse processo parece generalizado em português em que se tem uma série de verbos causativos relacionados a outros mediais sem variação formal: cristalizar 'tornar-se ou tornar cristalizado', branquear 'tornar-se ou tornar branco', envelhecer 'tornar-se ou tornar velho', entristecer 'tornar-se triste ou tornar triste', enlouquecer 'tornar-se louco ou tornar louco' (MALDONADO, 2007; LIMA, 2009; OLIVEIRA, 2015). Parte desses verbos é formada de 
adjetivos com o sufixo -ecer, a que se atribui o valor incoativo (CASTILHO, 1968 33 ; RIOTORTO et al., 2013), sufixo bastante produtivo no sistema verbal latino para marcar, nos tempos do infectum, aspecto incoativo ${ }^{34}$, a partir de verbos de estado ou diretamente de nomes adjetivos ou substantivos (DUARTE, 1990; HAVERLING, 1991), como ilustra o quadro 1.

\section{Quadro 1: Formações latinas com o sufixo -sco}

\begin{tabular}{|l|l|l|}
\hline \multicolumn{1}{|c|}{ Adjetivo/substantivo } & \multicolumn{1}{|c|}{ Verbo de estado } & \multicolumn{1}{c|}{ Verbo incoativo } \\
\hline senex, senis 'velho' & seneo, ere 'ser ou estar velho' & senesco, ere 'tornar-se velho' \\
\hline aurora, ae 'manhã' & & auroresco, ere 'tornar-se manhã' \\
\hline maturus, a, um 'maduro' & & maturesco, ere 'tornar-se maduro \\
\hline
\end{tabular}

Em português, não há esse padrão regular do latim. Todavia, por meio de derivação, convertem-se adjetivos (visão estativa) em verbos de mudança (incoativa): pálido > empalidecer (tornar-se pálido); doido > endoidecer (tornar-se doido); triste > entristecer (tornar-se triste); magro > emagrecer (tornar-se magro); duro > endurecer (tornar-se duro) (HLIBOWICKA-WĘGLARZ, 1998).

\section{A média perifrástica}

As paráfrases dos verbos incoativos, uma perífrase com ficar/tornar-se e particípio/adjetivo, constituem outra forma de expressão medial que se apresenta às vezes

\footnotetext{
33 Em geral, a formação é circunfixal, em que a uma base nominal se agrega um afixo descontínuo cujo segmento inicial pode ser es-, a-, en- e cujo segmento final é -ear, -ejar, -ecer, -izar: esverdear, esclarecer, apodrecer, anoitecer, enraivecer, entardecer, encolerizar, aterrorizar (BECHARA, 1999; RIO-TORTO, 2019).

${ }^{34} \mathrm{Na}$ literatura, o sentido mais comum para o sufixo -sco latino e o -ecer português é o inceptivo. Todavia, como discute Haverling (1991), a partir de vários exemplos do latim clássico e tardio, o valor mais comum do sufixo é o de mudança de estado, que, no latim arcaico, podia ser gradual, nas formas derivadas com -sco não prefixadas, ou súbita, nas formas derivadas com prefixo -sco prefixadas, o que reflete a complexidade do sistema aspectual do verbo latino.
} 
como alternativa à forma não perifrástica. A frase (11a), por exemplo, codifica um evento não provocado, atribuído a uma eventualidade: o capotamento. Embora a causa esteja codificada na oração, é desfocada ao ser expressa como um satélite de valor temporal (a causa precede o efeito: post hoc ergo propter hoc). Em (12), a causa não é expressa, por ser desconhecida como é explicitado no contexto.

(11) a. Veículo ficou destruído após capotamento na Portinari ${ }^{35}$

b. Uma mulher teve um ataque de fúria e destruiu o carro de o ex-marido em Campo Grande, Cariacica, na manhã de sábado (22). ${ }^{36}$

c. Para sua infelicidade, no entanto, ele destruiu o carro depois de batê-lo em uma árvore dirigindo bêbado ${ }^{37}$

d. O fogo alto se espalhou rapidamente e destruiu o carro. ${ }^{38}$

(12)De acordo com a Polícia Rodoviária, ninguém ficou ferido. Não há informações sobre o que causou o fogo. ${ }^{39}$

As frases (11b) e (11c) retratam uma situação causativa com sujeito agente. Todavia, em (11b), o agente é marcado por [+ controle] e [+ intencionalidade]: A mulher destruiu o carro do ex-marido voluntariamente, portanto, é mais agentivo que o sujeito de (11c), que representa uma situação similar à descrita em (11a), um acidente, mas representada por uma oração ativa: ele destruiu o carro. Trata-se de uma cadeia de eventos que acaba por atribuir ao sujeito a responsabilidade pelo resultado: o carro ficou destruido, embora ele não tenha tido a intenção de destruir:

(13) Cadeia de eventos

Ele dirigiu bêbado [voluntariamente] >Ele bateu na árvore [sem querer] >ele destruiu o carro [sem querer]

Na construção medial (11a), a oração focaliza o resultado do acidente, apontando a causa direta. Na realidade objetiva, não se sabia ainda o que havia motivado o capotamento.

\footnotetext{
${ }^{35} \mathrm{https}$ //gcn.net.br/noticias/399699/franca/2019/07/carro-capota-na-candido-portinari-e-deixa-dois-feridos ${ }^{36} \mathrm{https}$ //g1.globo.com/es/espirito-santo/noticia/2019/06/24/mulher-tem-ataque-de-furia-e-destroi-carro-do-exmarido-em-cariacica-es.ghtml

${ }^{37} \mathrm{http}$ :/esporte.ig.com.br/lutas/2012-12-06/anderson-silva-ganha-carro-de-r-1-milhao-de-presente-do-ufc.html ${ }^{38} \mathrm{https}$ //g1.globo.com/mg/minas-gerais/noticia/2019/06/21/carro-pega-fogo-em-bairro-da-regiao-noroeste-debelo-horizonte.ghtml

${ }^{39} \mathrm{https} / /$ g1.globo.com/sp/santos-regiao/noticia/2019/06/30/carro-pega-fogo-dentro-de-tunel-na-pista-de-subidada-rodovia-dos-imigrantes.ghtml
} 
Já na construção ativa, em (11c), atribui-se o efeito ao motorista como fonte de energia que provocou o evento ainda que involuntariamente, porque dirigiu bêbado. Na construção ativa de (11d), a fonte de energia externa é uma força natural, sem volição e sem controle, mas instigadora do processo.

Algumas construções com ficar + particípio/adjetivo alternam com construções intransitivas de valor incoativo ${ }^{40}$ que apresentam às vezes um clítico, especialmente, com verbos de processo mental: zangar-se/ficar zangado; preocupar-se/ficar preocupado; alegrar-se/ficar alegre; entristecer-selficar triste; animar-se/ficar animado; emocionarselficar emocionado (BORBA, 1996). Em (14), o par meu avô ficou doente/minha mãe adoeceu exprime a mudança de uma entidade que passou de um estado de [não estar doente] para outro estado de [estar doente], ou seja, ambas expressam incoatividade ${ }^{41}$.

\section{(14) a. Desde que meu avô ficou doente, ela ficou muito deprimida ${ }^{42}$. b. Minha mãe adoeceu e fui morar com minha avó ${ }^{43}$}

As construções diferem quanto ao fato de (14a) focalizar não só a mudança de estado, como (14b), mas também o resultado. Assim, ficar doente situa-se aspectualmente entre adoecer e estar doente:

a relação entre elas é a de um antes para um depois: "a maçã amadureceu" exprime um facto anterior a "a maçã ficou madura", podendo a segunda frase referir-se a um facto observado no momento presente, ao passo que a primeira só pode referir-se ao passado. (HERCULANO DE CARVALHO, 1984, p. 144-145)

Por situar-se no limite entre a mudança de estado e o resultado, construções com ficar $+v+d o$ permitem uma leitura de permansividade, como em (15), em que não se fala de um

\footnotetext{
${ }^{40}$ Nem toda construção medial perifrástica admite a alternância; ficar destruido, por exemplo, não alterna com destruiu(-se): $O$ carro ficou destruído - *O carro destruiu - *O carro se destruiu. Admite-se uma impessoal (a chamada passiva pronominal): Destruiu-se o carro para esconder da polícia.

${ }^{41}$ Ficar apresenta, em português, dois significados, o de permanência (significado básico, segundo LEHMANN, 2008) e o de mudança. O valor incoativo depende da construção em que o verbo figura (forma com que se combina; tempo/aspecto/modo verbal em que é empregado, contexto geral em que é usado).

${ }^{42} \mathrm{https}: / / \mathrm{www} . j \mathrm{j} . c o m . b r /$ saude/um-novo-olhar-para-a-doenca-do-seculo-21/

${ }^{43} \mathrm{https} / / / \mathrm{www} . g a z e t a o n l i n e . c o m . b r / n o t i c i a s / p o l i c i a / 2019 / 05 /$ influenciadora-digital--indiciamento-porestelionato-e-mal-entendido-1014180179.html
} 


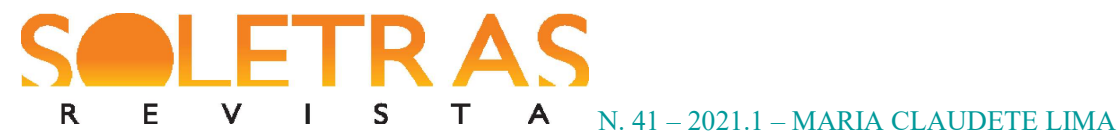

portão que estava fechado e tornou-se aberto, mas de um portão, que já estava aberto e ficaria (permaneceria) aberto.

(15) Os universitários afirmam que o portão lateral ficava aberto, o que facilitava o $\operatorname{acesso}^{44}$.

Nesse caso, a construção com ficar $+v+d o$ parece ter uma leitura agentiva, uma vez que admite uma oração infinitiva final (WHITAKER-FRANCHI, 1989), como mostram as alternativas em (16), artificialmente criadas.

(16) a. O guarda abriu o portão para facilitar o acesso.

b. O portão foi aberto para facilitar o acesso.

c. Abriu-se o portão para facilitar o acesso.

d. ? O portão (se) abriu para facilitar o acesso.

e. O portão ficou aberto para facilitar o acesso.

Essa possibilidade de leitura agentiva aproxima as construções com ficar $+v+d o$ das passivas, levando à sua inclusão em uma tipologia de construções passivas baseada no verbo auxiliar: passiva eventiva, formada com verbo ser e particípio; passiva adjetiva ou resultativa, formada por ficar + particípio/adjetivo; e passiva estativa, formada por estar + particípio/adjetivo (ESTRELA, 2013; MARTINS; NUNES, 2016). Se tais construções são agrupadas em uma mesma classe pela estrutura perifrástica similar, são separadas em subclasses pelo comportamento sintático-semântico: admissão ou não de um SP com valor agentivo; admissão ou não de advérbios agentivos (voluntariamente, propositadamente), produtividade de derivação com prefixo de negação (indissoluto/*indissolvido; incorreto/*incorrigido); combinação com tipos de predicados (resultativas tendem a ser usadas com eventos télicos, destruir o carro, mas não são compatíveis com estados: *ficar amado) (DUARTE; OLIVEIRA, 2010).

A indeterminação categorial das construções com ficar, ora consideradas passivas, ora médias, ora predicativas, deriva da própria polissemia do verbo ficar (LEHMANN, 2008) em combinação com o semantema do termo de valor adjetival com que se combina e do contorno têmporo-aspectual da oração. A construção com ficar que se enquadra no domínio

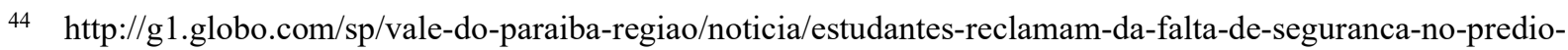
de-engenharia-da-unitau.ghtml
} 


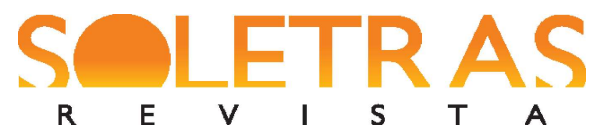

médio é a formada com particípio ou adjetivo que codifica uma visão de evento de mudança de estado não agentivo, como exemplificado em (11a), (12) e (14a).

\section{A média facilitativa}

Diferentemente dos tipos anteriores, a média facilitativa ou potencial é não eventiva, o que se reflete no uso de formas imperfectivas. São construções que focalizam a facilidade ou dificuldade de realização do processo, desfocalizando o agente. Em (17a), tem-se uma construção ativa: você compra fácil as chamadas blue chips. Em (17b), (17c), (17d) e (17e), tem-se a média facilitativa ou média potencial (VAN OSTEN, 1977; GÍVON, 1993; KEMMER, 1993), que, como as outras construções mediais já discutidas, não perfila o agente.

(17) a. Especificamente as chamadas blue chips, que sempre são alvo de cenários especulativos, por acumularem altos índices de liquidez - você compra fácil, vende fácil e perde fácil. ${ }^{45}$

b. na hora da despedida, no portão de ferro que se abre com dificuldade, Karen, a mais velha, pede que a reportagem deixe uma mensagem ${ }^{46}$

c. Mesmo tendo profissão, as portas nunca se abrem com facilidade para quem tem em o currículo prisões por furto e tráfico ${ }^{47}$

d. A dobradiça possui um design de dupla resistência o que permite ao notebook abrir com facilidade ${ }^{48}$

e. A porta de entrada deve abrir com facilidade e totalmente. Nada de portas que emperram ao abrir ou com móveis atrás de ela, que impede a abertura total ${ }^{49}$

Todavia, embora não perfilado, o agente nessas frases é conceitualmente concebido, pois a facilidade ou a dificuldade do processo deve-se à sua realização por um agente. Ao focalizar a dificuldade ou a facilidade do processo, a média potencial atribui certa

\footnotetext{
${ }^{45} \mathrm{http}$ ://www.infomoney.com.br/mercados/acoes-e-indices/noticia/5711063/quer-investir-bolsa-comece-formasimples-escolha-apenas-uma-acao

${ }^{46} \mathrm{http}$ ://esportes.estadao.com.br/noticias/futebol,familias-das-vitimas-do-acidente-do-itaquerao-esperam-por-in denizacao, 1120136

${ }^{47}$ http://www.midiamax.com.br/midiamais/livres-grades-presos-pelo-preconceito-ressocializacao-patinamercado-trabalho-367387

${ }^{48} \mathrm{http}$ ://www.techenet.com/2015/04/aspire-r11-e-a-nova-aposta-da-acer-para-o-mercado-dos-hibridos/

${ }^{49} \mathrm{http}$ //vidaeestilo.terra.com.br/horoscopo/feng-shui/feng-shui-dicas-para-ter-mais-prosperidade-em-suacasa,48cc3ca225d5c410VgnVCM3000009af154d0RCRD.html
} 


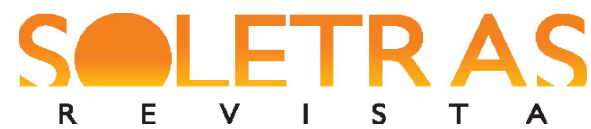

responsabilidade ao Afetado, pois o maior ou menor esforço requerido do Agente pressuposto dependerá de propriedades internas do Afetado: em 17b, o portão de ferro se abre com dificuldade devido a alguma propriedade interna (ferrugem, falta de lubrificação das ferragens etc.). O mesmo pode ser dito das demais frases. Em 17d, essa propriedade é explicitada no contexto reconstruindo-se a rede causal: a dobradiça de dupla resistência Cau $_{\text {permite }}{ }^{50}$ ao notebook $_{T m}$ abrir com facilidade. Embora a fonte de energia esteja explícita no contexto, disjungida do Tema que é sujeito da oração medial, trata-se de uma propriedade interna ao notebook, o que leva à baixa distinguibilidade (KEMMER, 1993) entre o Tema e a Fonte da cadeia causal.

Do exposto, evidencia-se como a codificação da noção de medialidade em português é variada. Todavia, isso não impede que se reconheçam propriedades gerais que permitem abrigar todas as construções aqui discutidas em uma mesma categoria, como se propõe a seguir.

\section{Considerações finais}

Os quatro tipos de construções médias apresentados, embora tenham suas especificidades, partilham as seguintes características: (a) mudança de estado não provocada; (b) afetação do sujeito; (c) topicalização do Afetado; (d) causa não perfilada. Algumas dessas propriedades são partilhadas por outras construções de voz. A passiva, por exemplo, apresenta as características (b), (c) e (d), mas não (a), prototipicamente. Também a construção impessoal compartilha as propriedades (b) e (d), mas não (c) e (a).

Isso permite dispor as construções de voz detransitivas em português em uma macrocategoria semântica em que os membros compartilham alguns traços, embora não todos, como propõe Givón (1984), para quem as categorias se formam pela interseção de uma ou várias propriedades típicas. Propõe-se que essa macrocategoria seja a não atribuição de causalidade e que as variadas construções nela dispostas se distribuam de modo fluido, de tal modo que alguns membros de uma dada subcategoria podem se aproximar ou afastar mais de membros de outra subcategoria que daquela a que pertencem. Assim, a média perifrástica se

\footnotetext{
${ }^{50}$ Segundo Johnson (1990), a permissão é uma estrutura conceitual, uma Gestalten, ligada à noção de Força: representa uma força potencial diante da ausência de barreiras ou forças opostas.
} 


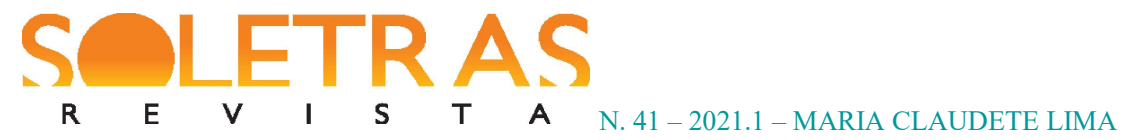

aproxima da passiva por codificar o resultado, e a média facilitativa se aproxima da impessoal por pressupor um agente humano.

Essa distribuição se tornaria mais complexa e refinada se se incluírem os subtipos semânticos de construções médias, como fez Kemmer (1993), de modo a se ter um mapeamento das construções de voz em português que permita entrever as relações apenas brevemente delineadas neste texto, o que poderá ser explorado em outro momento.

\section{Referências}

ALEXIADOU, A. The causative alternation revisited: constraints and variation. English Linguistics 32: 1, English Linguistic Society of Japan, p.1-12, 2015.

ALMEIDA, N. M. de. Gramática metódica da língua portuguesa. São Paulo: Saraiva, 1980.

BECHARA, E. Moderna gramática portuguesa. Rio de Janeiro: Lucerna, 1999.

BORBA, F. da S. Uma gramática de valência para o português. São Paulo: Ática, 1996.

CAMACHO, R. Em defesa da categoria de voz média no português. Revista D.E.L.T.A. 19:1, p. $91-122,2003$.

CAMACHO, R. G. Voz e atribuição de tópico. versão parcial do trabalho Construções de voz, apresentado no X Seminário do Projeto de Gramática do Português Falado, Campos de Jordão, SP, de 8 a 13/02/98, 2000.

CAMARA JR. J. M. História e estrutura da língua portuguesa. Rio de Janeiro: Padrão, 1985.

CANÇADO, M.; GODOY, L. Representações lexicais de classes verbais do português. Alfa. V. 56 (1). São Paulo, p.109-135, 2012.

CASTILHO, A.T. de. Introdução ao estudo do aspecto verbal na língua portuguesa. Marília: Faculdade de Filosofia, Ciências e Letras, 1968.

CIENKI, A. Frames, Idealized Cognitive Models, and Domains. In: GEERAERTS, D. and CUYCKENS, H. (Eds). The Oxford handbook of cognitive linguistics. New York: Oxford University Press, 2007. p. 27-47.

CÍRIACO, L.; CANÇADO, M. Inacusatividade e inergatividade no PB. Caderno de Estudos Linguísticos. 46 (2), p. 207-226, 2004.

CROFT, W. Voice: beyond control and affectedness. In: FOX, Barbara; HOPPER, Paul J. (ed) Voice: form and function. Amsterdam/Philadelphia: John Benjamins Publishing Company, 1994. p. 89-117. 


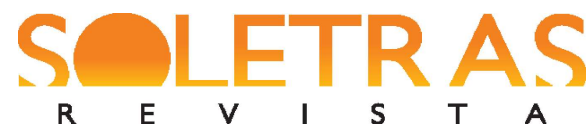

CUNHA, C.; CINTRA. Nova gramática do português contemporâneo. Rio de Janeiro: Nova Fronteira, 1985.

DAVIES, M.; FERREIRA, M. Corpus do português NOW. 1,4 bilhões de palavras. 20122019. Brigham Young University: Provo-UT, 2018. Disponível em: https://www. corpusdoportugues.org/now/. Acesso em: 20 jul. 2020.

DELANCEY, S. Transitivity in grammar and cognition. In: TOMLIN, R. S. Coherence and grounding in discourse. Amsterdam: John Benjamins, 1987. p.53-68. Disponível em: https://www.academia.edu/3929827/Transitivity_in_Grammar_and_Cognition. Acesso em: 10 jun. 2020.

DUARTE, I.; OLIVEIRA, F. Particípios resultativos. Textos selecionados, XXV Encontro Nacional da Associação Portuguesa de Linguística. Porto, APL, p. 397-408, 2010.

DUARTE, P. M. T. A derivação parassintética: uma abordagem sincrônica e diacrônica quanto aos aspectos gramaticais e semânticos. Dissertação (Mestrado em Estudos Linguísticos). Universidade Federal de Minas Gerais, Belo Horizonte, 1990.

DUARTE, P. M. T. Proposta para uma descrição do verbo quanto à categoria de voz. Revista do GELNE, v. 4, n. 2, p. 1-7, 2 mar. 2002. Disponível em: https://periodicos.ufrn.br/ gelne/article/view/9095. Acesso em: 10 jun. 2020.

ESTRELA, A. Estrutura passiva: uma visão tripartida. In: TEIXEIRA, M. et al. Ensinar e aprender num mundo plural. Escola Superior de Educação de Santarém/Universidade Federal de Minas Gerais. 2013. p. 99-135. Disponível em: https://repositorio.ipsantarem.pt/bitstream/ 10400.15/1136/1/ebook.pdf\#page=99. Acesso em: 15 jul. 2020.

GIVÓN, T. English grammar: a function-based introduction. Amsterdam: John Benjamins. v.1, 1993.

GIVÓN, T. Syntax: a functional-typological introduction. v. 1. Amsterdam: John Benjamins, 1984.

GIVÓN, T. Transitivity, topicality, and the ute impersonal passive. In HOPPER, P. J.; THOMPSON, S. A. (eds) Syntax and semantics: studies in transitivity. Vol.15. New York: Academic Press, 1982. p. 143-160.

GOLDBERG, A. A construction grammar approach to argument structure. Chicago: University of Chicago Press, 1995.

HALLIDAY, M.A.K. Estrutura e função da linguagem in: LYONS, J. (org.) Novos horizontes em linguística. São Paulo: Cultrix, 1976. p.134-160.

HAVERLING, G. On the sco-suffix, on prefixes and the development of the Latin verbal system. In: HERMAN, J. (Ed.) Linguistics studies on Latin. Amsterdam: John Benjamins, 1991. p.41-53. 
HERCULANO DE CARVALHO, J. G. Ficar em casa / ficar pálido: gramaticalização e valores aspectuais. In: HERCULANO DE CARVALHO, J. G.; SCHMIDT-RADEFELDT, J. (eds.), Estudos de linguística portuguesa. Coimbra: Coimbra, 1984. p. 57-75.

HLIBOWICKA-WĘGLARZ, B. Recursos morfológicos de integração aspectual na língua portuguesa. Acta Universitatis Palackianae Olomucensis. Romanica VII. Facultas Philosophica Philologica, 71. Lublin, 1998. p. 143-154.

HOPPER, P. J. e THOMPSON, S. A. Transitivity in grammar and discourse, Language, vol. 56. Baltimore, 1980. p.251-299. Disponível em: http://latina.phil2.uni-freiburg.de/raible/ Lehre/2006/Materialien/Hopper_Thompson.pdf . Acesso em: 10 jun. 2020.

JOHNSON, M. The body in the mind: the bodily basis of meaning, imagination and reason. Chicago: University of Chicago Press, 1990.

KEMMER, S. The middle voice. Amsterdam/Philadelphia: John Benjamins, 1993.

LAKOFF, G. Women, fire, and dangerous things: what categories reveal about the mind. Chicago/London: University of Chicago Press, 1987.

LANGACKER, R. W. Concept, image, and symbol. The cognitive basis of grammar. Berlin/New York, Mouton de Gruyter, 1991 b.

LANGACKER, R. W. Foundations of cognitive grammar. Descriptive application. Stanford/California: Stanford University Press, 1991a.

LANGACKER, Ronald W. Foundations of cognitive grammar: theoretical prerequisites. Stanford, California: Stanford University Press. v.1, 1987.

LEHMANN, C. A auxiliarização de ficar. In: PINTO DE LIMA, J.; SIEBERG, B. (eds.), Questions of language change. Lisboa: Colibri. 2008. p.9-26. Disponível em http://www.unierfurt.de/sprachwissenschaft/personal/lehmann/CL_Publ/ Acesso em: 12 jun. 2020.

LIMA, M. C. A não-atribuição de causalidade na Crônica Geral de Espanha de 1344.2009. 471 f. Tese (Doutorado em Linguística). Universidade Federal do Ceará, Fortaleza, 2009.

LYONS, J. Introdução à linguística teórica. São Paulo: Nacional, 1979.

MACAMBIRA, J. R. Estrutura do vernáculo. Fortaleza: EUFC, 1986.

MALDONADO, R. Grammatical voice in cognitive grammar. In:GEERAERTS, D.;CUYCKENS,H. (eds.). The Oxford handbook of cognitive linguistics. Oxford: Oxford University Press, 2007. p. 829-68.

MARTINS, A. M.; NUNES. J. Passives e se construcions. WETZELS, L. W.; COSTA, J.; MENUZZI, S. The handbook of Portuguese linguistics. John Wiley\& Sons, 2016. p. 318-337. Disponível em: https://onlinelibrary.wiley.com/doi/book/10.1002/9781118791844. Acesso em: 20 jul. 2020. 


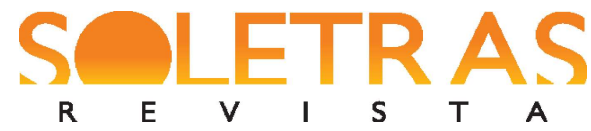

MELO, G. C. de. Gramática fundamental da língua portuguesa. Rio de Janeiro: Ao Livro Técnico, 1980.

OLIVEIRA, M. J. de. O morfema INCH e a alternância causativo-incoativa em PB. Domínios de Lingu@gem, v. 9, n. 3, p. 91-103,31 jul. 2015. Disponível em http://www.seer.ufu.br/ index.php/dominiosdelinguagem/article/view/28824. Acesso em: 20 jul. 2020.

RAPOSO, E. Verbo e sintagma verbal. In: Raposo, E. et al. (Orgs.). Gramática do Português (Vol II). Lisboa: Fundação Calouste Gulbenkian, 2013, cap. 28.

RIO-TORTO, G. et al. Gramática derivacional do português. Coimbra, Imprensa da Universidade de Coimbra, 2013.

RIO-TORTO, G. Prefixação, sufixação e parassíntese no português: harmonia e competição. Macabéa, v. 8, n.2, jul-dez, 2019, p.585-602, 2019.

ROCHA LIMA, L. H. da. Gramática normativa da língua portuguesa. Rio de Janeiro: José Olympio, 1992.

ROŚCIŃSKA-FRANKOWSKA, M. On derivation of causative and inchoative forms in Polish in comparison with English and other languages. Generative Linguistics in Wroctaw. No.1. Wrocław: Center for General and Comparative Linguistics, 2012. Disponível em: http://www.ifa.uni.wroc.pl/linguistics/documents/Onthederivation.pdf. Acesso em: 17 jul. 2020.

SAID ALI, M. Gramática histórica da língua portuguesa. São Paulo: Melhoramentos, 1964.

SHIBATANI, M. On the conceptual framework for voice phenomena. Linguistics. 44. p. $217-$ 269, 2006.

VAN OOSTEN, J. Subjects and Agenthood in English. Papers of $13^{\circ}$ Meeting of the Chicago Linguistic Society. Chicago, 1977. p. 459-471.

VESTERINEN, R. Subordinação adverbial: um estudo cognitivo sobre o infinitivo, o clítico se e as formas verbais finitas no português europeu. Doctoral Dissertation. Department of Spanish, Portuguese and Latin American studies. Stockholm: Stockholm University, 2006. Disponível em: http://su.diva-portal.org/smash/get/diva2:199744/FULLTEXT01.pdf. Acesso em: 10 jun. 2020.

WHITAKER-FRANCHI, R. C.M. As construções ergativas. 1989. 190 f. Dissertação (Mestrado em Linguística). IEL/Universidade Estadual de Campinas, Campinas, 1989.

WU, S.; CIENKI, A. Transitivity, events, and gesture: the case of the causative-inchoative alternation. Open Linguistics. De Gruyter, 5, 2019. p.311-331. 


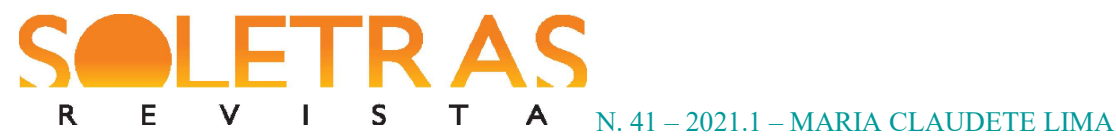

\title{
Typology of medial constructions in Portuguese: a cognitive-functional proposal
}

\begin{abstract}
This essay proposes a typology of medial constructions in Portuguese based on the Idealized Cognitive Model of Causality (LANGACKER, 1991a) called "billiard ball" and on the notion of transitivity proposed by Hopper and Thompson (1980). Therefore, it discusses central characteristics of middle voice and analyzes, regarding the form of codification, the expression of the cause, the type of event, the pragmatic motivation and the salience of the entities, in occurrences taken from the Corpus of Portuguese NOW (DAVIES; FERREIRA, 2018), which covers texts written from Brazil and Portugal, from 2012 to 2019. By considering the notion of an absolute construal (LANGACKER, 1991a), the study proposes a typology of medial constructions in Portuguese manifested in a lexical, syntactic, and peripheral form. The results suggest that the voice constructions inserted in the medial domain are different expressions of the same construct of causality nonattribution, which also includes passive and impersonal constructions.
\end{abstract}

Keywords: Middle voice. Causality. Absolute construal.

Recebido em: 21 de novembro de 2020.

Aceito em: 15 de dezembro de 2020. 